\title{
Mutational Analysis of the Sinorhizobium meliloti Short-Chain Dehydrogenase/Reductase Family Reveals Substantial Contribution to Symbiosis and Catabolic Diversity
}

\author{
Asha I. Jacob, Sirin A. I. Adham, David S. Capstick, Scott R. D. Clark, Tara Spence, and \\ Trevor C. Charles \\ Department of Biology, University of Waterloo, 200 University Avenue West, Waterloo, ON N2L 3G1, Canada
}

Submitted 21 November 2007. Accepted 6 March 2008.

\begin{abstract}
The short-chain dehydrogenase/reductase (SDR) family is one of the largest and most ubiquitous protein families in bacterial genomes. Despite there being a few well-characterized examples, the substrate specificities or functions of most members of the family are unknown. In this study, we carried out a large-scale mutagenesis of the SDR gene family in the alfalfa root nodule symbiont Sinorhizobium meliloti. Subsequent phenotypic analysis revealed phenotypes for mutants of 21 of the SDR-encoding genes. This brings the total number of $S$. meliloti SDR-encoding genes with known function or associated phenotype to 25 . Several of the mutants were deficient in the utilization of specific carbon sources, while others exhibited symbiotic deficiencies on alfalfa (Medicago sativa), ranging from partial ineffectiveness to complete inability to form root nodules. Five of the mutants had both symbiotic and carbon utilization phenotypes. These results clearly demonstrate the importance of the SDR family in both symbiosis and saprotrophy, and reinforce the complex nature of the interaction of $S$. meliloti with its plant hosts. Further analysis of the genes identified in this study will contribute to the overall understanding of the biology and metabolism of $S$. meliloti in relation to its interaction with alfalfa.
\end{abstract}

The rapid expansion of the known bacterial genome sequences, from both cultivated and uncultivated organisms, continues to radically alter microbiological research. Much effort is now expended toward the identification of the functions of novel genes that are discovered in the genome sequences, because this knowledge contributes toward the full understanding of the biology of the corresponding organisms.

Corresponding author: Trevor C. Charles; Telephone: 519888 4567, ext. 35606; Fax: 519746 0614; E-mail: tcharles@uwaterloo.ca

Current address of S. A. I. Adham: Department of Biomedical Sciences, Ontario Veterinary College, University of Guelph, Guelph, ON N1G 2W1, Canada.

Current address of D. S. Capstick: Department of Biology, McMaster University, 1280 Main St. West, Hamilton, ON L8S 4K1, Canada.

Current address of T. Spence: Department of Microbiology and Immunology, Queens University, 99 University Ave, Kingston, ON K7L 3N6, Canada.

* The $\boldsymbol{e}$-Xtra logo stands for "electronic extra" and indicates that four supplemental tables are published online.
The well-characterized $\alpha$-proteobacterium Sinorhizobium meliloti, whose genome sequence was made available in 2001 (Galibert et al. 2001), is a versatile model system for this type of research. There are several examples of the Rhiziobiales order of the $\alpha$-proteobacteria that form intimate interactions with eukaryal host cells, as pathogens or symbionts (Williams et al. 2007). Of these, S. meliloti forms alfalfa (Medicago sativa) root nodules in a symbiotic relationship during which atmospheric nitrogen $\left(\mathrm{N}_{2}\right)$ is converted to ammonia for the benefit of the plant. Such symbiotic $\mathrm{N}_{2}$ fixation is of ecological importance, because it represents a major input of fixed $\mathrm{N}$ into ecosystems. It is also important for agricultural systems, relieving the need for economically and ecologically expensive nitrogen fertilizers.

$S$. meliloti cells are capable of using a variety of carbon substrates for growth, including sugars, sugar alcohols, amino acids, organic acids, and phenolics (Aneja and Charles 1999; Arias and Martinez-Drets 1976; Charles and Aneja 1999; Charles and Finan 1991; Dunn 1998; Finan et al. 1991; Gage and Long 1998; Gosselin et al. 2001; Graham 1964; Irigoyen et al. 1990; Johnson et al. 1966; Parke and Ornston 1984; Parker and Graham 1964); this capacity to utilize a wide spectrum of substrates probably contributes to cell survival and proliferation in the nutritionally complex soil and rhizosphere environments. Several candidates for contributing to the catabolic capacity of $S$. meliloti are found within the short-chain dehydrogenases/reductases (SDR) superfamily of proteins (Jörnvall et al. 1999; Kallberg et al. 2002a), also known as the tyrosine dependent oxidoreductases. The SDR enzymes carry out $\mathrm{NAD}(\mathrm{P})(\mathrm{H})$-dependent oxidation and reduction reactions on specific compounds, and have the N-terminal coenzyme binding motif GXXXGXG associated with the Rossman fold and the catalytic Ser-Tyr-Lys triad that incorporates the YXXXK motif (Filling et al. 2002; Kallberg and Persson 2006; Kallberg et al. 2002b; Persson et al. 2003). Although members of this family are easily identified based on phylogenetic and sequence characteristics, this identification does not predict the substrate specificity of the individual enzymes. Experimentally based knowledge of the substrates corresponding to orthologous SDR subclasses is required for the interpretation of genomics-enabled gene expression studies and microbial community analyses.

The S. meliloti genome contains 77 genes that are catalogued within the Pfam adh_short family (PF00106) (Finn et al. 2006), but only a few of these genes are of known function. SMb21010 (bdhA) encodes D-3-hydroxybutyrate dehydro- 
genase (EC 1.1.1.30) as the first gene in an operon that also encodes the two subunits of a xanthine oxidase (Aneja and Charles 1999). SMc03878 encodes acetoacetyl-CoA reductase (phbB) (EC 1.1.1.36) (Aneja et al. 2004; Tombolini et al. 1995) and shares an operon with SMc03789, encoding acetylCoA acetyltransferase (EC 2.3.1.9). SMa0854 (nodG) and SMc00572 ( $f a b G)$ encode redundant 3-oxoacyl-ACP reductase (EC 1.1.1.100) enzymes that are involved in fatty acid elongation (Lopez-Lara and Geiger 2001). This is particularly relevant to the provision of fatty acids required for synthesis of the lipochitin oligosaccharide nodulation signal molecule.

A few of the other SDR family members are sufficiently well conserved that their function is predicted with high confidence. SMc02322, which also contains an aldolase domain, is part of the rhamnose utilization operon. It has been shown previously that mutants of the Rhizobium leguminosarum ortholog are unable to catabolize rhamnose (Richardson et al. 2004). The substrate is probably a phosphorylated derivative of rhamnose. SMc02273 is predicted to encode a translationally fused version of a transcript that, in another wild-type isolate of $S$. meliloti, strain Rm41, is composed of several open reading frames (ORF) that are involved in K-antigen capsular polysaccharide synthesis (Kiss et al. 2001). SMc00326 and SMc00005 are predicted to encode enoyl ACP reductase enzymes (EC 1.3.1.9) involved in fatty acid biosynthesis.

In the study reported here, we set out to disrupt each of the $S$. meliloti genes that are predicted to encode SDR family members. Through phenotypic analysis of the resulting mutants, we have attempted to deduce the specific functions of the genes. To our knowledge, this is the first report of the attempted disruption of the complete complement of SDRencoding genes in any organism.

\section{RESULTS AND DISCUSSION}

\section{Identification of SDR-encoding genes in the $S$. meliloti genome.}

Given the moderately high level of sequence conservation within the SDR family, primary screening of the $6.7-\mathrm{Mb}$ genome by BLASTP (Altschul et al. 1990) was possible. The sequence of the previously well-characterized SDR D-3-hydroxybutyrate dehydrogenase (BdhA) of $S$. meliloti was used as query, and products with greater than $23 \%$ amino acid sequence identity to BdhA were considered as putative members of the SDR family. Further screening for the SDR-specific ADH SHORT PROSITE consensus motif [LIVSPADNK] - $\mathrm{x}(9)-$ $\{\mathrm{P}\}-\mathrm{x}(2)-\mathrm{Y}-[\mathrm{PSTAGNCV}]-[$ STAGNQCIVM] $[\mathrm{STAGC}]-\mathrm{K}-\{\mathrm{PC}\}-[\mathrm{SAGFYR}]-[$ LIVMSTAGD $]-\mathrm{x}-$ $\{\mathrm{K}\}-[\mathrm{LIVMFYW}]-\{\mathrm{D}\}-\mathrm{x}-\{\mathrm{YR}\}-[$ LIVMFYWG APTHQ] - [GSACQRHM] using PatScan (Hulo et al. 2006) identified a subset of 56 of these genes, while the Pfam adh_short family (PF00106) (Finn et al. 2006) based on this same motif identified 77 genes. Although SMa2019, SMc02040, and SMc02356 were not identified in the Pfam subset, they were included in the study because they showed the presence of the PROSITE consensus sequence. Interestingly, SMc02356 has been annotated as an ABC transporter even though it includes the SDR motif. SMc02273 and SMb20974, identified as SDR by Pfam, were not included in this study. SMc02273 appears to be a composite of proteins that contains multiple domains, of which one is an SDR domain. These domains are usually found encoded by individual genes organized as an operon in other organisms. If SMc02273 were functional, it would appear to be a multifunctional enzyme and not exclusively an SDR. SMb20974 does not have the PROSITE consensus sequence and appears to have a truncated SDR domain. Based on these analyses, 78 SDR-encod- ing genes in the $S$. meliloti genome were retained for this study (Supplementary Table S1).

Protein structure studies have revealed the importance of a glycine-rich T-G- $\mathrm{X}_{3}-\mathrm{G}-\mathrm{X}-\mathrm{G}$ motif and an $\mathrm{N}-\mathrm{N}-\mathrm{A}-\mathrm{G}$ motif for the maintenance of the structure of the central $\beta$-sheet involved in coenzyme binding and in determining the direction of the reaction (Filling et al. 2002; Kallberg and Persson 2006; Kallberg et al. 2002b; Persson et al. 2003). These motifs are highly conserved and are not a part of the PROSITE consensus sequence. Moreover, the active site tetrad constituting the residues N-S-Y-K (part of the PROSITE consensus) is conserved in this group of proteins. Using multiple-sequence alignment facilitated by ClustalW (Ramu et al. 2003) to generate multiple sequence alignments (data not shown), we determined that the $\mathrm{T}-\mathrm{G}-\mathrm{X}_{3}-\mathrm{G}-\mathrm{X}-\mathrm{G}$ motif was present in each predicted SDR, except in SMa1367, SMa0389, SMc00005, SMc00326, and SMc02040. Also, the NNAG motif was absent in SMa2019, SMa1629, SMc00326, SMc00005, and SMc02040. The active site residue asparagine was not found in SMa2019.

The 78 SDR-encoding genes are distributed on all three $S$. meliloti replicons, 21 on each of the megaplasmids pSymA and pSymB and 36 on the chromosome. Substrates for most of these SDR enzymes have yet to be determined. The predicted proteins range from 136 to 699 amino acids in length. The smallest SDR identified, SMa2019, has much of the N-terminal region absent when compared with the others. The longest SDR identified, SMc02322, has two other well-characterized Pfam domains: an aldolase domain and a domain corresponding to epimerase. The ortholog of SMc02322 has been studied in $R$. leguminosarum as part of the rhamnose utilization operon (Richardson et al. 2004). Three of the remaining SDR identified, $p h b B$, nod $G$, and $b d h A$, have been previously characterized in $S$. meliloti, as indicated above.

\section{Construction of SDR mutants.}

Phenotypic analysis can be a very powerful approach to the determination of gene function. Therefore, in order to understand the role of the SDR-encoding genes in S. meliloti, each SDR gene was systematically mutated and the phenotype of each mutant was analyzed. RmP110, a derivative of Rm1021 in which a frameshift mutation in pstC is corrected (Yuan et al. 2006), was used as the parental strain. Our strategy was to create gene fusions in the gentamicin-resistant $\left(\mathrm{Gm}^{\mathrm{r}}\right)$ reporter vector pTH1703 (Cowie et al. 2006). Because pTH1703 is unable to replicate in $S$. meliloti, a segment of each gene of interest was used to facilitate single homologous recombination events, thereby disrupting the gene.

To construct the mutants, pTH1703 or pVIK112 carrying the ORF fragments were mobilized from Escherichia coli DH5 $\alpha$ into RmP110 by triparental mating and transconjugants selected using streptomycin and gentamicin for pTH1703 and streptomycin and neomycin for pVIK112. Cointegrates resulting from a single recombination event will have two incomplete copies of the gene. One copy will be the intact, promoterless copy of the gene and the second copy will be the truncated version of the gene, with the promoter transcriptionally fused to a reporter gene. Mutations in $b d h A(\mathrm{SMb} 21010)$ were made using both pVIK112 and pTH1703, and, in both cases, yielded the expected D-3-hydroxybutyrate utilization phenotype. Such mutations are expected to be polar on downstream genes in the same operon.

Of the 78 genes identified as SDR, 3-bdhA (SMb21010), nodG (SMa0854), and $p h b B$ (SMc03878) - have been characterized previously. Of the remaining SDR, we were not able to recover fabG (SMc00572) mutants, although an $S$. meliloti fabG mutant has been reported (Miller-Williams et al. 2006). Thus, each of the 78 genes identified as SDR have been mutated. 
Single-crossover mutagenesis in $S$. meliloti using vectors such as pTH1703 has proven to be extremely reliable (Cowie et al. 2006). To ensure that this was the case in our hands, 14 representative mutants were screened by polymerase chain reaction (PCR) to confirm whether recombination resulting in the mutation had occurred in the target gene. For this purpose, a primer upstream from the start codon of the gene of interest (forward primer) was used in a PCR reaction with a primer designed from gus or gfp on pTH1703 (reverse primer) (Supplementary Table S2). In each case, the obtained amplification product confirmed the desired recombination event. Having confidence in the nature of the mutants, the collection was further characterized in terms of role in substrate utilization and symbiosis.

\section{SDR-encoding genes are required for utilization of specific carbon sources.}

Given the importance of oxidation reactions in catabolic pathways, we expected that at least some of the SDR mutants would be unable to utilize specific carbon sources to support growth. Each of the SDR mutants was screened on 81 different substrates (Table 1) as $0.1 \%$ sole carbon source on rhizobium mineral medium (RMM) agar. The list was compiled based on published reports on specific carbon source utilization by $S$. meliloti (Charles and Finan 1991; Graham 1964; Parker and Graham 1964). Whenever available, mutants constructed in each of the two orientations in the integration vector were screened.
Single colonies of the mutants were streaked for single isolates and the plates were incubated at $30^{\circ} \mathrm{C}$ for up to 4 weeks, during which time they were scored for growth by comparison with the growth of RmP110. Each screen was performed three times, and each strain exhibiting a phenotype was further confirmed by testing fresh RmP110 transductants of the mutations for the same phenotype.

From the growth pattern on the different sole carbon sources, only one of the genes, SMc00778, appears to be required for prototrophy. The SMc00778 mutants were unable to grow on any of the carbon sources except proline. This suggests that a SMc00778 mutation results in proline auxotrophy, because this mutant was unable to utilize any of the carbon sources unless the media was supplemented with proline. As shown in Table 2, 18 other SDR genes were required for growth on specific carbon sources.

The phenotype of some of the SDR mutants confirmed previously reported results or predictions. The SMc02322 mutants are not able to utilize rhamnose and, from previously published results, it is known that this region is equivalent to the region responsible for rhamnose catabolism in $R$. leguminosarum (Richardson et al. 2004). The inability of the SMc01500 mutants to utilize sugar alcohols is consistent with the location of the gene in a region annotated to be involved in sorbitol metabolism (Galibert et al. 2001).

The SMb20210 mutant showed very weak growth on most substrates and lies adjacent to a series of genes predicted to be

Table 1. Carbon sources for short-chain dehydrogenase/reductase mutant strain screening

\begin{tabular}{|c|c|c|}
\hline Pentoses and derivatives & $\alpha$-Galactosides & Amino acids and derivatives \\
\hline D-ribose & Melibiose & L-alanine \\
\hline 2-Deoxy-D-ribose & Raffinose & L-lysine \\
\hline D-xylose & & L-ornithine \\
\hline D-lyxose & $\beta$-Galactosides & L-proline \\
\hline D-arabinose & Lactose & Trans-4-hydroxy-L-proline \\
\hline L-arabinose & Lactulose & Glycyl-L-proline \\
\hline Methyl- $\beta$-D-xylopyranoside & & L-serine \\
\hline D-ribono- $\gamma$-lactone & & L-homoserine \\
\hline L-rhamnose & $\alpha$-Glucosides & Glutamine \\
\hline & Trehalose & $\gamma$-Aminobutyric acid \\
\hline Hexoses and derivatives & Turanose & Alanineamide \\
\hline D-glucose & Maltose & Glycine-aspartate \\
\hline L-glucose & Sucrose & Alanine-glycine \\
\hline D-galactose & Maltotriose & Glutamate-glutamate \\
\hline D-fructose & Dextrin & \\
\hline D-mannose & Inulin & Nucleotides and derivatives \\
\hline D-tagatose & & Uridine \\
\hline D-fucose & $\beta$-Glucosides & Thymidine \\
\hline L-fucose & Gentiobiose & Adenine hemisulfate \\
\hline Palatinose & Cellobiose & \\
\hline Arbutin & Salicin & Organic acids \\
\hline D-galactono- $\gamma$-lactone & & D-malic acid \\
\hline Methyl- $\alpha$-D-galactopyranoside & & L-malic acid \\
\hline Methyl- $\beta$-D-galactopyranoside & Sugar alcohols & Fumaric acid \\
\hline$N$-acetyl-D-glucosamine & Sorbitol & Sodium succinate \\
\hline$N$-acetyl-D-galactosamine & Adonitol & Monomethyl succinate \\
\hline \multirow[t]{14}{*}{ 3-O-methyl-D-glucopyranose } & D-mannitol & Citric acid \\
\hline & Meso-erythritol & DL-bromosuccinic acid \\
\hline & Galactitol & Pyruvic acid \\
\hline & Maltitol & Aminovaleric acid \\
\hline & Inositol & Formic acid \\
\hline & Glycerol & Lactic acid \\
\hline & D-arabitol & \\
\hline & L-arabitol & \\
\hline & Alcohols & \\
\hline & Ethanol & \\
\hline & Propanol & \\
\hline & Sugar phosphates & \\
\hline & Glucose-1-phosphate & \\
\hline & Fructose-6-phosphate & \\
\hline
\end{tabular}


involved in pyrroloquinoline quinone (PQQ) synthesis. This is interesting given that PQQ is a cofactor for quinoprotein dehydrogenases. Mutants of two other SDR genes, SMc02486 and SMa0719, exhibited generally poor growth on most carbon sources. Of these, SMc02486 lies in a region that includes several genes encoding enzymes involved in the TCA cycle (Dymov et al. 2004). The growth phenotype observed for the mutant may be due to TCA cycle defects; however, determination of this requires further experimentation. Mutation of the pSymA gene SMa0719, lying adjacent to predicted arginine transport and catabolism genes, results in growth deficiency in all tested carbon sources except glucose, malate, succinate, fructose, D-lyxose, and D-xylose. A rationale for this phenotype is not readily apparent.

Three SDR-encoding genes from different regions of the chromosome, SMc01204, SMc02034, and SMc02356, are required for utilization of ribonic- $\gamma$-lactone. SMc01204 is predicted to have an N-terminal transmembrane domain and SMc02356 appears to be part of an ABC transporter system. SMc02034 is located adjacent to an ABC transporter system. Little is known about bacterial catabolism of this carbon source, which is presumably freely interconvertible with Dribose via reduction or oxidation. Further study of these mutants should help to uncover the significance of ribonolactone metabolism in S. meliloti.

In the same region as SMc02034, there is an interesting cluster of four other SDR-encoding genes: SMc02037, SMc02039, SMc02040, and SMc02041. Only one of these, the downstream SMc02041, exhibited a carbon utilization phenotype. It was unable to utilize monomethyl succinate. Further investigation is required to determine the role of this SDR-rich cluster of genes.

The SMb21159 gene lies immediately upstream of a putative $\beta$ - $N$-acetylhexosaminidase-encoding gene, SMb21160. Fusions to the nearby ABC transporter gene, SMb21151, indicated that its expression was induced by galactosamine. Rather than having a phenotype on galactosamine-containing media, SMb21159 mutants exhibited growth deficiency on glucose-1phosphate and succinate. We do not yet understand the metabolic basis for this growth phenotype; however, it could sug- gest a pathway for galactosamine catabolism that includes a glucose-1-phosphate intermediate.

SMb20492 and SMb20493 lie adjacent to each other in the genome and are transcribed in the same direction, with SMb20493 situated upstream of SMb20492. Downstream of these SDR are genes annotated to be involved in sugar transport, a carbohydrate kinase, and a D-fucose phosphate aldolase (fucA2). This is consistent with the inability of the SMb20492 and SMb20493 mutants to utilize fucose. The inability of these mutants to utilize succinate, monomethyl-succinate, leucine, and lysine perhaps reflects a role in a pathway common to utilization of fucose and these carbon sources, or might be due to common auxiliary requirements of these catabolic pathways.

The genes SMb20073 and SMb20076 are divergently expressed from each other, with SMb20073 being immediately upstream of an $\mathrm{ABC}$ transporter gene cluster. The first gene in this cluster, SMb20072, was induced by myo-inositol (Mauchline et al. 2006); however, our screens did not reveal a phenotype on myo-inositol for these two SDR mutants but, rather, indicated deficiency in utilization of D-fucose, lysine, leucine, and proline. Mutants of another pSymB-encoded SDR, SMb20750, are unable to grow on ornithine and leucine. This is located in a region that has previously been suggested to be involved in the catabolism of branched-chain amino acids isoleucine, leucine, and valine (Charles and Aneja 1999; Miyamoto et al. 2003).

The weak growth of the SMb20409 mutants on galactitol and D-mannose is consistent with the recent finding that the adjacent gene, SMb20410, encoding part of an ABC transporter system, is induced by galactitol (= dulcitol) and D-mannose (Mauchline et al. 2006). This is also consistent with the previously reported dulcitol growth phenotype for deletions of this region (Charles and Finan 1991). The weak growth of the SMb21111 mutants on D- and L-fucose is consistent with the location of this gene as a distal member of an operon that has been found to be induced by both D- and L-fucose (Mauchline et al. 2006).

As indicated above, transductants of each of the mutants were tested to negate the chance that a phenotype may be due to an unknown second site mutation. As a further check on the

Table 2. Short-chain dehydrogenase/reductase mutant strains showing a free-living or symbiotic phenotype

\begin{tabular}{|c|c|c|c|}
\hline Mutant ORF ${ }^{a}$ & Gene & Carbon utilization deficiency $^{b}$ & Symbiotic phenotype \\
\hline SMa0719* & $\ldots$ & All except glucose, DL-malic acid, succinate, fructose, D-lyxose, D-xylose & $\mathrm{Fix}^{+/-}$ \\
\hline SMb20073 & $\ldots$ & D-fucose, lysine, leucine, proline & Fix $^{+}$ \\
\hline SMb20076 & $\ldots$ & D-fucose, lysine, leucine, proline & $\mathrm{Fix}^{+}$ \\
\hline SMb20210* & $\ldots$ & All except glucose, DL-malic acid, succinate, fructose, D-lyxose, D-xylose, D-ribose & $\mathrm{Fix}^{-}$ \\
\hline SMb20214 & $\ldots$ & None & $\mathrm{Fix}^{+/-}$ \\
\hline SMb20409 & $\ldots$ & Galactitol, D-mannose & Fix $^{+}$ \\
\hline SMb20492 & $\ldots$ & D-fucose, succinate, monomethyl-succinate, leucine, lysine & $\mathrm{Nod}^{-}$ \\
\hline SMb20493 & $\ldots$ & D-fucose, succinate, monomethyl-succinate, leucine, lysine & $\mathrm{Fix}^{+/-}$ \\
\hline SMb20750 & & D-fucose, glucose-1-phosphate, leucine, ornithine & $\mathrm{Fix}^{+}$ \\
\hline SMb21010 & $b d h A$ & None (D-3-hydroxybutyrate deficiency confirmed as control) & $\mathrm{Fix}^{+}$ \\
\hline SMb21111 & $\ldots$ & D-fucose and L-fucose & $\mathrm{Fix}^{+}$ \\
\hline SMb21159 & $\ldots$ & Succinate, glucose-1-phosphate & $\mathrm{Fix}^{+}$ \\
\hline $\mathrm{SMc} 00005$ & fabII & None & $\mathrm{Fix}^{-}$ \\
\hline SMc00326 & $f a b I 2$ & None & $\mathrm{Fix}^{-}$ \\
\hline SMc00778 & $\ldots$ & Proline auxotroph & Fix $^{+}$ \\
\hline SMc01204 & $\ldots$ & Ribonic- $\gamma$-lactone & $\mathrm{Fix}^{+}$ \\
\hline SMc01500 & smoS & Mannitol, maltitol, sorbitol, myo-inositol, meso-erythritol & $\mathrm{Fix}^{+}$ \\
\hline SMc02034 & $\ldots$ & Ribonic- $\gamma$-lactone & Fix $^{+}$ \\
\hline SMc02041 & $\ldots$ & Monomethyl succinate & $\mathrm{Fix}^{+}$ \\
\hline $\mathrm{SMc} 02322$ & $\ldots$ & L-rhamnose & $\mathrm{Fix}^{+}$ \\
\hline $\mathrm{SMc} 02356$ & $\ldots$ & Ribonic- $\gamma$-lactone, monomethyl succinate & Fix $^{+}$ \\
\hline SMc02486* & $\ldots$ & $\begin{array}{l}\text { All except glucose, D-lyxose, L-leucine, } N \text {-acetyl-D-glucosamine, inositol, } N \text {-acetyl-D-- } \\
\text { galactosamine, sorbitol, meso-erythritol, maltitol }\end{array}$ & Fix $^{-}$ \\
\hline
\end{tabular}

\footnotetext{
${ }^{a} \mathrm{ORF}=$ open reading frame; $*$ shows poor growth on most substrates, except those indicated.
}

${ }^{\mathrm{b}}$ All growth phenotypes are in comparison to the wild type strain RmP110. 
robustness of the screen, each of the SDR-encoding genes from the $S$. meliloti ORFeome (Schroeder et al. 2005) (kindly provided by I. Oresnik and T. Finan) were transferred into the Gateway-compatible expression vector pCO37 (Clark, unpublished). pCO37 clones containing the ORF of SDR showing a carbon utilization phenotype were then introduced into the corresponding mutant background. The resulting transconjugants were tested for complementation of the loss of function. All carbon utilization phenotypes could be complemented in this manner.

\section{Symbiotic phenotype of SDR mutant strains.}

The SDR mutants were screened under nitrogen-deficient conditions on alfalfa seedlings in both vermiculite containing Leonard assemblies (Leonard 1943) and in agar slants to determine the involvement of any of the SDR-encoding genes in symbiosis. After 4 weeks, the plants inoculated with the parental strain RmP110 were healthy and green, with pink nodules, compared with the uninoculated control plants that were stunted, chlorotic, and devoid of nodules. Although inoculation with most of the SDR mutants yielded plants that were indistinguishable from the plants inoculated with the parental strain, a substantial number of the SDR mutant-inoculated plants exhibited clear deficiencies in symbiosis (Supplementary Table S3). This observation was reinforced by comparison of the shoot dry weights, and the nodules were further analyzed by light microscopy. For each mutant exhibiting a symbiotic phenotype, the mutation was reintroduced into RmP110 by transduction (Finan et al. 1984), and testing of the resulting transductants yielded the same results.

The screen revealed eight of the SDR-encoding genes to be required for the formation of normal, nitrogen-fixing nodules

Table 3. Distribution of orthologs of 25 Sinorhizobium meliloti short-chain dehydrogenase/reductase (SDR)-encoding genes in genomes of members of the Rhizobiales $^{\mathrm{a}}$

\begin{tabular}{|c|c|c|c|c|c|c|c|c|}
\hline SDR & Smed & RI & $\mathbf{R e}$ & Ml & $\mathbf{B j}$ & At & Oa & Bm \\
\hline SMa0719 & $\begin{array}{l}89 \% \\
\text { Smed_3585 }\end{array}$ & $\begin{array}{l}\ldots \\
\ldots\end{array}$ & $\begin{array}{l}\ldots \\
\ldots\end{array}$ & $\begin{array}{l}\ldots \\
\ldots\end{array}$ & $\begin{array}{l}41 \% \\
\text { blr1409 }\end{array}$ & $\begin{array}{l}67 \% \\
\text { Atu5465 }\end{array}$ & $\begin{array}{l}\ldots \\
\ldots\end{array}$ & $\begin{array}{l}\ldots \\
\ldots\end{array}$ \\
\hline SMa0854 & $98 \%$ & $80 \%$ & $31 \%$ & $86 \%$ & $60 \%$ & $79 \%$ & $74 \%$ & $73 \%$ \\
\hline$(\operatorname{nod} G)$ & Smed_6193 & RL1558 & RHE_CH01443 & $\operatorname{mlr} 7850$ & blr4083 & Atu1095 & Oant_0571 & BMEI1477 \\
\hline \multirow[t]{2}{*}{ SMb20073 } & $95 \%$ & $78 \%$ & $79 \%$ & $\ldots$ & $\ldots$ & $62 \%$ & $72 \%$ & $\ldots$ \\
\hline & Smed_4064 & pRL110421 & RHE_PE00299 & $\ldots$ & $\ldots$ & Atu5276 & Oant_4304 & $\ldots$ \\
\hline \multirow[t]{2}{*}{ SMb20076 } & $87 \%$ & $\ldots$ & $65 \%$ & $\ldots$ & $\ldots$ & $\ldots$ & $\ldots$ & $\ldots$ \\
\hline & Smed_4061 & $\ldots$ & RHE_CH02674 & $\ldots$ & $\ldots$ & $\ldots$ & $\ldots$ & $\ldots$ \\
\hline \multirow[t]{2}{*}{ SMb20210 } & $92 \%$ & $48 \%$ & $49 \%$ & $\ldots$ & $66 \%$ & $\ldots$ & $\ldots$ & $\ldots$ \\
\hline & Smed_3913 & RL1854 & RHE_PF00540 & $\ldots$ & blr5937 & $\ldots$ & $\ldots$ & $\ldots$ \\
\hline \multirow[t]{2}{*}{ SMb20214 } & $64 \%$ & $74 \%$ & $\ldots$ & $62 \%$ & $\ldots$ & $48 \%$ & $\ldots$ & $\ldots$ \\
\hline & Smed_5531 & RL4052 & $\ldots$ & mll6686 & $\ldots$ & Atu5444 & $\ldots$ & $\ldots$ \\
\hline \multirow[t]{2}{*}{ SMb20409 } & $93 \%$ & $\ldots$ & $\ldots$ & $72 \%$ & $\ldots$ & $\ldots$ & $\ldots$ & $\ldots$ \\
\hline & Smed_3714 & & $\ldots$ & mlr5248 & $\ldots$ & $\ldots$ & $\ldots$ & $\ldots$ \\
\hline \multirow[t]{2}{*}{ SMb20492 } & $\ldots$ & $67 \%$ & $\ldots$ & $57 \%$ & $48 \%$ & $\ldots$ & $\ldots$ & $\ldots$ \\
\hline & $\ldots$ & RL3778 & $\ldots$ & mll1982 & blr0293 & $\ldots$ & $\ldots$ & $\ldots$ \\
\hline \multirow[t]{2}{*}{ SMb20493 } & $\ldots$ & $72 \%$ & $70 \%$ & $62 \%$ & $60 \%$ & $\ldots$ & $70 \%$ & $\ldots$ \\
\hline & $\ldots$ & RL3779 & RHE_CH03352 & mll1981 & bll4020 & $\ldots$ & Oant_3448 & $\ldots$ \\
\hline \multirow[t]{2}{*}{ SMb20750 } & $91 \%$ & $\ldots$ & $\ldots$ & $\ldots$ & $\ldots$ & $47 \%$ & $\ldots$ & $\ldots$ \\
\hline & Smed_4244 & $\ldots$ & $\ldots$ & $\ldots$ & $\ldots$ & Atu2417 & $\ldots$ & $\ldots$ \\
\hline SMb21010 & $92 \%$ & $69 \%$ & $67 \%$ & $57 \%$ & $66 \%$ & $65 \%$ & $58 \%$ & $\ldots$ \\
\hline$(b d h A)$ & Smed_4500 & RL3569 & RHE_CH03123 & mll3632 & blr1488 & Atu 2308 & Oant_1122 & $\ldots$ \\
\hline \multirow{2}{*}{ SMb21111 } & $96 \%$ & $83 \%$ & $84 \%$ & $78 \%$ & $52 \%$ & $61 \%$ & $79 \%$ & $\ldots$ \\
\hline & Smed_4971 & pRL110599 & RHE_PE00431 & mll4781 & bl13914 & Atu4466 & Oant_031 & $\ldots$ \\
\hline \multirow[t]{2}{*}{ SMb21159 } & $91 \%$ & $77 \%$ & $76 \%$ & $46 \%$ & $\ldots$ & $73 \%$ & $47 \%$ & $46 \%$ \\
\hline & Smed_4652 & pRL110503 & RHE_PE00386 & mlr4150 & $\ldots$ & Atu2597 & Oant_3894 & BMEII0543 \\
\hline SMc00005 & $98 \%$ & $80 \%$ & $80 \%$ & $78 \%$ & $76 \%$ & $89 \%$ & $80 \%$ & $80 \%$ \\
\hline$(f a b I I)$ & Smed_0512 & RL1011 & RHE_CH00938 & mlr7458 & blr2629 & Atu0757 & Oant_0535 & BMEI1512 \\
\hline SMc00326 & $95 \%$ & $85 \%$ & $83 \%$ & $75 \%$ & $76 \%$ & $82 \%$ & $78 \%$ & $77 \%$ \\
\hline$(f a b I 2)$ & Smed_3448 & RL0118 & RHE_CH00109 & mll5565 & blr0771 & Atu0149 & Oant_0741 & BMEI1958 \\
\hline SMc00572 & $97 \%$ & $89 \%$ & $89 \%$ & $88 \%$ & $64 \%$ & $89 \%$ & $80 \%$ & $81 \%$ \\
\hline$(f a b G)$ & Smed_0745 & RL1558 & RHE_CH01443 & mlr7850 & blr4083 & Atu 1095 & Oant_0571 & BMEI1477 \\
\hline \multirow[t]{2}{*}{ SMc00778 } & $92 \%$ & $68 \%$ & $\ldots$ & $72 \%$ & $\ldots$ & $\ldots$ & $\ldots$ & $\ldots$ \\
\hline & Smed_032 & RL0975 & $\ldots$ & mlr4172 & $\ldots$ & $\ldots$ & $\ldots$ & $\ldots$ \\
\hline \multirow[t]{2}{*}{ SMc01204 } & $87 \%$ & $72 \%$ & $\ldots$ & $\ldots$ & $\ldots$ & $\ldots$ & $\ldots$ & $\ldots$ \\
\hline & Smed_1269 & RL3838 & $\ldots$ & $\ldots$ & $\ldots$ & $\ldots$ & $\ldots$ & $\ldots$ \\
\hline \multirow[t]{2}{*}{ SMc01500 } & $93 \%$ & $52 \%$ & $64 \%$ & $78 \%$ & $\ldots$ & $65 \%$ & $64 \%$ & $\ldots$ \\
\hline & Smed_2354 & RL0650 & RHE_PC00218 & mll4921 & $\ldots$ & Atu3164 & Oant_3850 & $\ldots$ \\
\hline \multirow[t]{2}{*}{ SMc02034 } & $94 \%$ & $57 \%$ & $42 \%$ & $42 \%$ & $58 \%$ & $43 \%$ & $\ldots$ & $\ldots$ \\
\hline & Smed_2445 & RL0645 & RHE_CH02402 & mll7334 & blr3225 & Atu1897 & $\ldots$ & $\ldots$ \\
\hline \multirow[t]{2}{*}{ SMc02041 } & $88 \%$ & $48 \%$ & $\ldots$ & $\ldots$ & $\ldots$ & $\ldots$ & $48 \%$ & $\ldots$ \\
\hline & Smed_2462 & RL1748 & $\ldots$ & $\ldots$ & $\ldots$ & & Oant_4068 & $\ldots$ \\
\hline \multirow[t]{2}{*}{ SMc02322 } & $94 \%$ & $74 \%$ & $74 \%$ & $79 \%$ & $\ldots$ & $74 \%$ & $74 \%$ & $\ldots$ \\
\hline & Smed_0223 & pRL110415 & RHE_PE00291 & mlr5708 & $\ldots$ & Atu3485 & Oant_3572 & $\ldots$ \\
\hline \multirow[t]{2}{*}{ SMc02356 } & $94 \%$ & $\ldots$ & $\ldots$ & $\ldots$ & $\ldots$ & $\ldots$ & $\ldots$ & $\ldots$ \\
\hline & Smed_5345 & $\ldots$ & $\ldots$ & $\ldots$ & $\ldots$ & $\ldots$ & $\ldots$ & $\ldots$ \\
\hline \multirow[t]{2}{*}{ SMc02486 } & $93 \%$ & $70 \%$ & $70 \%$ & $68 \%$ & $61 \%$ & $\ldots$ & $49 \%$ & $\ldots$ \\
\hline & Smed_2937 & RL4430 & RHE_CH03884 & mll4297 & bl10450 & $\ldots$ & Oant_2512 & $\ldots$ \\
\hline SMc03878 & $94 \%$ & $83 \%$ & $82 \%$ & $79 \%$ & $74 \%$ & $78 \%$ & $\ldots$ & $\ldots$ \\
\hline$(p h b B)$ & Smed_3116 & RL4620 & RHE_CH04019 & mlr3848 & blr3725 & Atu 2770 & $\ldots$ & $\ldots$ \\
\hline
\end{tabular}

${ }^{a}$ Abbreviations are as follows: Smed, Sinorhizobium medicae; R1, Rhizobium leguminosarum bv. viciae; Re, R. etli; Ml, Mesorhizobium loti; Bj, Bradyrhizobium japonicum; At, Agrobacterium tumefaciens; Oa, Ochrobactrum anthropi; Bm, Brucella melitensis. Only those matches above $40 \%$ are reported as potential orthologs. Only one $f a b G / n o d G$ ortholog was detected in all except $S$. medicae, and these were designated as fabG in each case. 
on alfalfa (Table 2). For these mutants, the phenotypes ranged from $\mathrm{Nod}^{-}$, in which no nodules were formed, to the formation of abnormal-looking nodules accompanied by evidence of complete or partial nitrogen starvation $\left(\mathrm{Fix}^{-}\right.$or $\left.\mathrm{Fix}^{+-}\right)$. The $\mathrm{Fix}^{-}$phenotype corresponds to $<25 \%$ shoot dry weight of the plants inoculated with the wild type strain, whereas Fix ${ }^{+/}$corresponds to 25 to $75 \%$ of the shoot dry weight of the positive control. The SMb20492 mutants were the only mutants that were unable to form nodules. Interestingly, mutation of the upstream gene SMb20493 did not abolish nodulation but instead yielded nodules that were white and more elongated than those formed by the parental strain, and the plants were only partially nitrogen starved. The nature of the relationship between the symbiotic phenotypes and the carbon utilization phenotype of these two mutants demands further study. The other mutations that resulted in partial nitrogen starvation were those in SMa0719, which exhibited a complex carbon utilization phenotype, and SMb20214, which had no carbon utilization deficiencies. Nodules formed by SMa0719 mutants were white and more elongated than the nodules formed by the parental strain, whereas the nodules formed by the SMb20214 appeared similar to those formed by the parental strain. Inoculation with four of the SDR mutants (SMb20210, SMc02486, SMc00005, and SMc00326) resulted in complete nitrogen starvation. Nodules formed by mutants of SMc00005 and SMc00326, both annotated as $f a b I$ orthologs encoding enoyl-ACP reductase enzymes (EC 1.3.1.9) involved in fatty acid biosynthesis, exhibited severe abnormalities. Roots inoculated by the SMc00005 mutants were thick and swollen, with very few lateral roots present, and nodules only formed very infrequently, whereas the nodules formed on the SMc00326 mutant-inoculated roots were very small and white. Light microscopy revealed that bacteria were not visible in the SMc00326 mutant nodules (data not shown). The nodules formed by SMb20210 mutants were white and elongated, whereas the nodules formed by SMc02486 mutants were smaller in size and more numerous. In both SMb20210 and SMc02486 mutant-induced nodules, the plant cells were found to be replete with bacteria (light microscopy, data not shown).

\section{Distribution of SDR orthologs in other genomes.}

The genome sequences of numerous other $\alpha$-proteobacteria are completed and available (Williams et al. 2007). We examined the distribution of orthologs of each of the 25 SDR-encoding genes for which phenotype or functions have now been associated. This analysis was limited to the very closely related S. medicae (unpublished) (GenBank accession number $\mathrm{NC}_{-}$ 009636); the other major root nodule bacteria R. leguminosarum (Young et al. 2006), R. etli (Gonzalez et al. 2006), Mesorhizobium loti (Kaneko et al. 2000), and Bradyrhizobium japonicum (Kaneko et al. 2002); the plant pathogen Agrobacterium tumefaciens (Wood et al. 2001); and the human intracellular pathogens Ochrobactrum anthropi (unpublished) (GenBank accession number NC_009667 to NC_009672) and Brucella melitensis (DelVecchio et al. 2002) (Table 3). Each SDR sequence was compared with the genomic data of these eight bacteria using BLASTP (Altschul et al. 1990) at the National Center for Biotechnology Information, and values above $40 \%$ amino acid sequence identity were reported as potential orthologs. Only three of the genes, the well-conserved fabII (SMc00005), fabI2 (SMc00326), and $f a b G$ (SMc00572), were found in all eight of the genomes. The fabI gene, encoding enoyl-ACP reductase, is well known as the target of the popular antimicrobial agent triclosan (Sivaraman et al. 2004). The only other SDR-encoding gene with an ortholog in B. melitensis was SMb21159, which was present in all except Bradyrhizobium japonicum.
Although $O$. anthropi is acknowledged as a close relative of Brucella spp. (Williams et al. 2007), it shares a considerably greater number of SDR orthologs with $S$. meliloti. This could reflect its more versatile lifestyle, including association with nutrient-rich soil environments. It will be interesting to determine whether the $O$. anthropi orthologs of those SDR-encoding genes that have a link to symbiosis will be shown to have a similar involvement in pathogenesis.

As expected, most of the SDR in S. meliloti exhibited very high sequence identity with their orthologs in $S$. medicae, its closest relative with a very similar nodulation host range. Notable exceptions were the adjacent genes SMb20492 and SMb20493, both of which had no orthologs in S. medicae or A. tumefaciens. SMb20492 had orthologs in each of the other rhizobia except $R$. etli, and SMb20493 had orthologs in each of the rhizobia and also in $O$. anthropi. Considering the shared host range and recent evolutionary history of $S$. meliloti and $S$. medicae, the immediate question concerns what genes play the role of these missing genes in the $S$. medicae symbiosis. Interestingly, the best matches for SMb20492 were from Burkholderia ambifaria (ZP_01552904, unpublished) and B. dolosa (ZP_00983133, unpublished), both at $76 \%$ amino acid sequence identity. The best match for SMb20493 was from Gluconacetobacter diazotrophicus Pal5 (YP_001602914, unpublished), at $77 \%$ identity.

Intriguingly, two of the SDR, SMc01204 and SMc02356, were Sinorhizobium specific. They were found only in $S$. meliloti and $S$. medicae, and $S$. meliloti mutants of both of these genes were unable to utilize the same carbon source, ribonic- $\gamma$-lactone. It remains to be determined whether the utilization of this carbon source might hold special value in some aspect of their symbiotic interactions with the medic plants.

\section{Concluding remarks.}

Our work builds on previous pregenomic and postgenomic studies that revealed loci involved in symbiotic and catabolic functions (Charles and Finan 1991; Luo et al. 2005; Mauchline et al. 2006; Oresnik et al. 2000), and reinforces the stature of $S$. meliloti as a robust model organism for investigation of host-microbe interactions and bacterial cell biology and physiology. The collection of post-genomic experimental tools for $S$. meliloti is impressive, with platforms for transcriptional profiling (Barnett and Fisher 2006; Barnett et al. 2004; Rüberg et al. 2003), proteomics (Chen et al. 2003), and metabolomics (Barsch et al. 2004). Functional genomics activities are further supported by the availability of the Gateway-compatible ORFeome clone library (Schroeder et al. 2005) and signature-tagged transposon (Pobigaylo et al. 2006) and plasmid insertion or gene fusion (Cowie et al. 2006) mutant collections.

The results reported in this article confirm that members of the SDR family make significant contributions to the symbiotic and saprophytic life of $S$. meliloti. Although the symbiotic phenotypes are interesting in their own right and further investigations are sure to lead to insight into the symbiotic relationship, it will be equally interesting to establish links between catabolism of specific carbon sources and symbiosis. We still do not know the substrate specificities for most of the SDR enzymes; however, we have taken an important step toward gathering that knowledge. This will be particularly important in the context of provision of experimental validation of new molecular docking techniques aimed at the prediction of SDR substrate specificity (Favia et al. 2008). Finally, we note the striking number of pSymB-located genes identified in this study, which reinforces the role of pSymB in the auxiliary functions related to symbiosis. 


\section{MATERIALS AND METHODS}

Bacterial strains, plasmids, and growth conditions.

$S$. meliloti RmP110, the wild type used in this study, is a derivative of $\mathrm{Rm} 1021$ with the point mutation in pstC corrected (Yuan et al. 2006). Culture methods in tryptone yeast (TY), Luria-Bertani, and RMM, and the concentration of antibiotics, were as described previously (Wang et al. 2006). Screening for carbon utilization phenotype was done on RMM (Broughton et al. 1986) supplemented with a single carbon source at a final concentration of $0.1 \%$. The 81 carbon sources tested are listed in Table 1. Plasmids used in this study and the phage used for transduction are listed in Supplementary Table S4.

\section{Plasmid construction and insertion mutagenesis.}

SDR gene DNA fragments (approximately 600 bp) were amplified by PCR from $S$. meliloti RmP110 genomic DNA with specific primers for each gene. The primers were defined on one end by the start codon. For SMa2019, the shortest gene in our collection, a fragment of $270 \mathrm{bp}$ was amplified. All PCR was carried out using Taq DNA polymerase (MBI Fermentas) or Pfu DNA polymerase (Promega Corp.). PCR products were cloned into an intermediary vector pGEM-T Easy Vector (Promega Corp.) in the T7 proximal orientation. The inserts were then released by digesting with NotI or EcoRI, purified with GFX PCR DNA and Gel Band Purification Kit (GE Healthcare), and ligated to NotI-digested and dephosphorylated pTH1703 (Cowie et al. 2006) or EcoRI-cut and dephosphorylated pVIK112 (Kalogeraki and Winans 1997), followed by E. coli $\mathrm{DH} 5 \alpha$ (Hanahan 1983) transformation. The orientation of the inserts in each of the pTH1703 clones was confirmed by PCR using the gfp and gus primers and the corresponding forward primer that was used in the original amplification. Both orientations were retained if available. The orientation of the inserts in the pVIK112 clones was determined by PCR using the pVIK112-lac primer and the corresponding forward primer. Only clones with inserts in the same orientation as the lac reporter gene were retained. For six of the genes (SMa0326, SMa0959, SMa1629, SMb20662, SMc01157, and SMc01955), PCR amplification products were not successfully obtained; therefore, we made use of clones from the $S$. meliloti ORFeome (Schroeder et al. 2005). The S. meliloti ORFeome consists of each of the 6,204 ORF identified in the genome, cloned into pMK2010. Using appropriate restriction enzymes, internal fragments of these genes were subcloned into pTH1703. A 393-bp fragment of HaeIII-digested SMa1629, a 343-bp fragment of HincII-digested SMa0959, a 687-bp fragment of AluI-digested SMa0326, and a 329-bp fragment of BmgBI-cut SMc01955 were ligated to SwaI-cut, dephosphorylated pTH1703. Similarly, 616- and 285-bp fragments of EagIdigested SMb20662 and SMc01157, respectively, were ligated to NotI-cut, dephosphorylated pTH1703. Resulting plasmid constructs were mobilized from DH5 $\alpha$ into wild-type strain $S$. meliloti $\mathrm{RmP} 110$ by triparentental mating using E. coli $\mathrm{DH} 5 \alpha$ (pRK600) as helper (Finan et al. 1986). Transconjugants were isolated on TY agar medium containing streptomycin and gentamicin (for pTH1703) or streptomycin and neomycin (for pVIK112), and were subjected to at least two rounds of singlecolony streak purification.

\section{Plant assays.}

Two-day-old alfalfa (Medicago sativa var. Iroquois) seedlings were transferred to Jensen's (Jensen 1942) nitrogen-free agar slants or Jensen's saturated vermiculite in modified Leonard assemblies (Leonard 1943), as previously described (Aneja et al. 2005). Each slant contained one seedling and five seedlings were planted per assembly. The seedlings were kept in a growth chamber $\left(16 \mathrm{~h}\right.$ of light at $25^{\circ} \mathrm{C}$ and $8 \mathrm{~h}$ of dark at $20^{\circ} \mathrm{C}$, light intensity $300 \mu$ moles $\mathrm{m}^{-2} \mathrm{~s}^{-1}$ ). Two days following seedling transfer, inoculation was carried out with $5 \mathrm{ml}$ (assemblies) or $0.1 \mathrm{ml}$ (slants) of a 1:50 water dilution of a saturated TY culture. Plants were grown for 4 to 6 weeks and examined for nodulation phenotype and symptoms of nitrogen starvation indicative of ineffective symbiosis. Shoot dry weight of 4week-old plants was determined after separating the root and shoot systems and drying at $65^{\circ} \mathrm{C}$ for at least 10 days. Shoot dry weight of five plants from each of the three pots per strain was measured. The values are presented as the average weight per group of five plants, with standard deviation calculated using data from three pots.

\section{Light microscopy.}

Nodules were fixed in $10 \%$ formalin for $24 \mathrm{~h}$ and dehydrated by washing in a gradient of ethanol $(20 \%, 1 \times$ for 10 $\min ; 50 \%, 1 \times$ for $10 \mathrm{~min} ; 70 \%, 3 \times$ for $10 \mathrm{~min} ; 95 \%, 2 \times$ for 10 $\mathrm{min}$; and $100 \%, 2 \times$ for $10 \mathrm{~min})$. Thereafter, the nodules were washed in xylene/ethanol $(1: 1 ; 1 \times$ for $10 \mathrm{~min})$, xylene $(2 \times$ for $10 \mathrm{~min})$, paraffin/xylene $(1: 1 ; 1 \times$ for $10 \mathrm{~min})$, and paraffin $(2 \times$ for $5 \mathrm{~min}$ ) and embedded in paraffin for sectioning. Using a microtome, 5 - $\mu \mathrm{m}$-thick sections were obtained, were placed in water on a slide coated with albumin, and were dried on a slide dryer at $60^{\circ} \mathrm{C}$ for $48 \mathrm{~h}$. The sections were washed in xylene ( $1 \times$ for $5 \mathrm{~min}$ and $1 \times$ for $3 \mathrm{~min}$ ), $100 \%$ ethanol ( $1 \times$ for $5 \mathrm{~min}$ and $1 \times$ for $3 \mathrm{~min}), 70 \%$ ethanol ( $1 \times$ for $5 \mathrm{~min}), 50 \%$ ethanol ( $1 \times$ for $3 \mathrm{~min}$ ), and distilled water $(1 \times$ for $1 \mathrm{~min})$. They were stained in toluidine blue $(\mathrm{pH} 4.5)$ for $20 \mathrm{~s}$, washed in distilled water $(2 \times$ for $1 \mathrm{~min})$, rehydrated by washing in a gradient of ethanol $(50 \%, 1 \times$ for $3 \mathrm{~min}$; $70 \%, 1 \times$ for $5 \mathrm{~min}$; and $100 \%, 1 \times$ for $5 \mathrm{~min}$ and $1 \times$ for $3 \mathrm{~min}$ ), rinsed in xylene $(2 \times$ for $5 \mathrm{~min}$ ), and mounted using permount (Fisher Scientific). The slides were air dried for $48 \mathrm{~h}$ and observed using a Nikon ALPHAPHOT-2 YS2 light microscope at $\times 40$ and $\times 400$ magnification, and digital images were captured.

\section{ACKNOWLEDGMENTS}

This research was supported by funding from Genome Canada through the Ontario Genomics Institute and Ontario Research and Development Challenge Fund, and Natural Sciences and Engineering Research Council of Canada. We are grateful to D. Weber for assistance with the light microscopy, I. Oresnik and T. Finan for the ORFeome clones, M. Kahn and his group for construction and distribution of the ORFeome libraries, and S. C. Winans for pVIK112. We also thank an anonymous reviewer for pointing out the Burkholderia and Gluconacetobacter matches for SMb20492 and SMb20493.

\section{LITERATURE CITED}

Altschul, S. F., Gish, W., Miller, W., Myers, E. W., and Lipman, D. J. 1990. Basic local alignment search tool. J. Mol. Biol. 215:403-410.

Aneja, P., and Charles, T. C. 1999. Poly-3-hydroxybutyrate degradation in Rhizobium (Sinorhizobium) meliloti: Isolation and characterization of a gene encoding 3-hydroxybutyrate dehydrogenase. J. Bacteriol. 181:849-857.

Aneja, P., Dai, M., Lacorre, D. A., Pillon, B., and Charles, T. C. 2004. Heterologous complementation of the exopolysaccharide synthesis and carbon utilization phenotypes of Sinorhizobium meliloti Rm1021 polyhydroxyalkanoate synthesis mutants. FEMS (Fed. Eur. Microbiol. Soc.) Microbiol. Lett. 239:277-283.

Aneja, P., Zachertowska, A., and Charles, T. C. 2005. Comparison of the symbiotic and competition phenotypes of Sinorhizobium meliloti PHB synthesis and degradation pathway mutants. Can. J. Microbiol. 51:599604.

Arias, A., and Martinez-Drets, G. 1976. Glycerol metabolism in Rhizobium. Can. J. Microbiol. 22:150-153.

Barnett, M. J., and Fisher, R. F. 2006. Global gene expression in rhizobiallegume symbiosis. Symbiosis 42:1-24. 
Barnett, M. J., Toman, C. J., Fisher, R. F., and Long, S. R. 2004. A dualgenome Symbiosis Chip for coordinate study of signal exchange and development in a prokaryote-host interaction. Proc. Natl. Acad. Sci. U.S.A. 101:16636-16641.

Barsch, A., Patschkowski, T., and Niehaus, K. 2004. Comprehensive metabolite profiling of Sinorhizobium meliloti using gas chromatographymass spectrometry. Funct. Integr. Genomics 4:219-230.

Broughton, W. J., Wong, C. H., Lewin, A., Samrey, U., Myint, H., Meyer, H., Dowling, D. N., and Simon, R. 1986. Identification of Rhizobium plasmid sequences involved in recognition of Psophocarpus, Vigna, and other legumes. J. Cell Biol. 102:1173-1182.

Charles, T. C., and Aneja, P. 1999. Methylmalonyl-CoA mutase encoding gene of Sinorhizobium meliloti. Gene 226:121-127.

Charles, T. C., and Finan, T. M. 1991. Analysis of a 1,600-kilobase Rhizobium meliloti megaplasmid using defined deletions generated in vivo. Genetics 127:5-20.

Chen, H., Teplitski, M., Robinson, J. B., and Rolfe, B. G. 2003. Proteomic analysis of wild-type Sinorhizobium meliloti responses to N-Acyl homoserine lactone quorum. J. Bacteriol. 5029-5036

Cowie, A., Cheng, J., Sibley, C. D., Fong, Y., Zaheer, R., Patten, C. L., Morton, R. M., Golding, G. B., and Finan, T. M. 2006. An integrated approach to functional genomics: Construction of a novel reporter gene fusion library for Sinorhizobium meliloti. Appl. Environ. Microbiol. 72:7156-7167.

DelVecchio, V. G., Kapatral, V., Redkar, R. J., Patra, G., Mujer, C., Los, T., Ivanova, N., Anderson, I., Bhattacharyya, A., Lykidis, A., Reznik, G. Jablonski, L., Larsen, N., D’Souza, M., Bernal, A., Mazur, M., Goltsman, E., Selkov, E., Elzer, P. H., Hagius, S., O'Callaghan, D., Letesson, J. J., Haselkorn, R., Kyrpides, N., and Overbeek, R. 2002. The genome sequence of the facultative intracellular pathogen Brucella melitensis. Proc. Natl. Acad. Sci. U.S.A. 99:443-448.

Dunn, M. F. 1998. Tricarboxylic acid cycle and anaplerotic enzymes in rhizobia. FEMS (Fed. Eur. Microbiol. Soc.) Microbiol. Rev. 22:105123

Dymov, S. I., Meek, D. J., Steven, B., and Driscoll, B. T. 2004. Insertion of transposon Tn5tac1 in the Sinorhizobium meliloti malate dehydrogenase $(m d h)$ gene results in conditional polar effects on downstream TCA cycle genes. Mol. Plant-Microbe Interact. 17:1318-1327.

Favia, A. D., Nobeli, I., Glaser, F., and Thornton, J. M. 2008. Molecular docking for substrate identification: The short-chain dehydrogenases/ reductases. J. Mol. Biol. 375:855-874.

Filling, C., Berndt, K., Benach, J., Knapp, S., Prozorovski, T., Nordling, E., Ladenstein, R., Jörnvall, H., and Oppermann, U. 2002. Critical residues for structure and catalysis in short-chain dehydrogenases/ reductases. J. Biol. Chem. 277:25677-25684.

Finan, T. M., Hartweig, E., LeMieux, K., K., B., Walker, G. C., and Signer, E. R. 1984. General transduction in Rhizobium meliloti. J. Bacteriol 159:120-124.

Finan, T. M., Kunkel, B., De Vos, G. F., and Signer, E. R. 1986. Second symbiotic megaplasmid in Rhizobium meliloti carrying exopolysaccharide and thiamine synthesis genes. J. Bacteriol. 167:66-72.

Finan, T. M., McWhinnie, E., Driscoll, B., and Watson, R. J. 1991. Complex symbiotic phenotypes result from gluconeogenic mutations in Rhizobium meliloti. Mol. Plant-Microbe Interact. 4:386-392.

Finn, R. D., Mistry, J., Schuster-Böckler, B., Griffiths-Jones, S., Hollich, V., Lassmann, T., Moxon, S., Marshall, M., Khanna, A., Durbin, R., Eddy, S. R., Sonnhammer, E. L. L., and Bateman, A. 2006. Pfam: Clans, web tools and services. Nucleic Acids Res. 34:247-251.

Gage, D. J., and Long, S. R. 1998. Alpha-galactoside uptake in Rhizobium meliloti: Isolation and characterization of agpA, a gene encoding a periplasmic binding protein required for melibiose and raffinose utilization. J. Bacteriol. 180:5739-5748.

Galibert, F., Finan, T. M., Long, S. R., Puhler, A., Abola, P., Ampe, F., Barloy-Hubler, F., Barnett, M. J., Becker, A., Boistard, P., Bothe, G., Boutry, M., Bowser, L., Buhrmester, J., Cadieu, E., Capela, D., Chain, P., Cowie, A., Davis, R. W., Dreano, S., Federspiel, N. A., Fisher, R. F., Gloux, S., Godrie, T., Goffeau, A., Golding, B., Gouzy, J., Gurjal, M., Hernandez-Lucas, I., Hong, A., Huizar, L., Hyman, R. W., Jones, T. Kahn, D., Kahn, M. L., Kalman, S., Keating, D. H., Kiss, E., Komp, C., Lelaure, V., Masuy, D., Palm, C., Peck, M. C., Pohl, T. M., Portetelle, D., Purnelle, B., Ramsperger, U., Surzycki, R., Thebault, P., Vandenbol, M., Vorholter, F. J., Weidner, S., Wells, D. H., Wong, K., Yeh, K. C., and Batut, J. 2001. The composite genome of the legume symbiont Sinorhizobium meliloti. Science 293:668-672.

Gonzalez, V., Santamaria, R. I., Bustos, P., Hernandez-Gonzalez, I. Medrano-Soto, A., Moreno-Hagelsieb, G., Janga, S. C., Ramirez, M. A. Jimenez-Jacinto, V., Collado-Vides, J., and Davila, G. 2006. The partitioned Rhizobium etli genome: Genetic and metabolic redundancy in seven interacting replicons. Proc. Natl. Acad. Sci. U.S.A. 103:38343839
Gosselin, I., Wattraint, O., Riboul, D., Barbotin, J., and Portais, J. 2001. A deeper investigation on carbohydrate cycling in Sinorhizobium meliloti. FEBS (Fed. Eur. Biochem. Soc.) Lett. 499:45-49.

Graham, P. H. 1964. Studies on the utilization of carbohydrates and Krebs cycle intermediates by Rhizobia, using agar plate method. Antonie Leeuwenhoek 30:68-72.

Hanahan, D. 1983. Studies on transformation of Escherichia coli with plasmids. J. Mol. Biol. 166:557-580.

Hulo, N., Bairoch, A., Bulliard, V., Cerutti, L., De Castro, E., LangendijkGenevaux, P. S., Pagni, M., and Sigrist, C. J. A. 2006. The PROSITE database. Nucleic Acids Res. 34:227-230.

Irigoyen, J. J., Sanchez-Diaz, M., and Emerich, D. W. 1990. Carbon metabolism enzymes of Rhizobium meliloti cultures and bacteroids and their distribution within alfalfa nodules. Appl. Environ. Microbiol. 56:2587-2589.

Jensen, H. L. 1942. Nitrogen fixation in leguminous plants. I. General characters of root-nodule bacteria isolated from species of Medicago and Trifolium in Australia. Proc. Linn. Soc. N. S. W. 66:98-108.

Johnson, G. V., Evans, H. J., and Ching, T. 1966. Enzymes of the glyoxylate cycle in rhizobia and nodules of legumes. Plant Physiol. 41:13301336

Jörnvall, H., Hoog, J. O., and Persson, B. 1999. SDR and MDR: Completed genome sequences show these protein families to be large, of old origin, and of complex nature. FEBS (Fed. Eur. Biochem. Soc.) Lett. 445:261-264

Kallberg, Y., and Persson, B. 2006. Prediction of coenzyme specificity in dehydrogenases/reductases. A hidden Markov model-based method and its application on complete genomes. FEBS (Fed. Eur. Biochem. Soc.) J. 273:1177-1184.

Kallberg, Y., Oppermann, U., Jörnvall, H., and Persson, B. 2002a. Shortchain dehydrogenase/reductase (SDR) relationships: A large family with eight clusters common to human, animal, and plant genomes. Protein Sci. 11:636-641.

Kallberg, Y., Oppermann, U., Jörnvall, H., and Persson, B. 2002b. Shortchain dehydrogenases/reductases (SDRs). Eur. J. Biochem. 269:44094417

Kalogeraki, V. S., and Winans, S. C. 1997. Suicide plasmids containing promoterless reporter genes can simultaneously disrupt and create fusions to target genes of diverse bacteria. Gene 188:69-75.

Kaneko, T., Nakamura, Y., Sato, S., Asamizu, E., Kato, T., Sasamoto, S., Watanabe, A., Idesawa, K., Ishikawa, A., Kawashima, K., Kimura, T., Kishida, Y., Kiyokawa, C., Kohara, M., Matsumoto, M., Matsuno, A., Mochizuki, Y., Nakayama, S., Nakazaki, N., Shimpo, S., Sugimoto, M., Takeuchi, C., Yamada, M., and Tabata, S. 2000. Complete genome structure of the nitrogen-fixing symbiotic bacterium Mesorhizobium loti. DNA Res. 7:331-338.

Kaneko, T., Nakamura, Y., Sato, S., Minamisawa, K., Uchiumi, T. Sasamoto, S., Watanabe, A., Idesawa, K., Iriguchi, M., Kawashima, K. Kohara, M., Matsumoto, M., Shimpo, S., Tsuruoka, H., Wada, T. Yamada, M., and Tabata, S. 2002. Complete genomic sequence of nitrogen-fixing symbiotic bacterium Bradyrhizobium japonicum USDA110. DNA Res. 9:189-197.

Kiss, E., Kereszt, A., Barta, F., Stephens, S., Reuhs, B. L., Kondorosi, A. and Putnoky, P. 2001. The rkp-3 gene region of Sinorhizobium melilot Rm41 contains strain-specific genes that determine K antigen structure. Mol. Plant-Microbe Interact. 14:1395-1403.

Leonard, L. T. 1943. A simple assembly for use in testing cultures of rhizobia. J. Bacteriol. 45:523-547.

Lopez-Lara, I. M., and Geiger, O. 2001. The nodulation protein NodG shows the enzymatic activity of an 3-oxoacyl-acyl carrier protein reductase. Mol. Plant-Microbe Interact. 14:349-357.

Luo, L., Yao, S., Becker, A., Ruberg, S., Yu, G., Zhu, J., and Cheng, H. 2005. Two new Sinorhizobium meliloti LysR-type transcriptional regulators required for nodulation. J. Bacteriol. 187:4562-4572.

Mauchline, T. H., Fowler, J. E., East, A. K., Sartor, A. L., Cowie, A., Hosie, A. H. F., Poole, P. S., and Finan, T. M. 2006. Mapping the Sinorhizobium meliloti 1021 solute-binding protein-dependent transportome. Proc. Natl. Acad. Sci. U.S.A. 103:17933-17938.

Miller-Williams, M., Loewen, P. C., and Oresnik, I. J. 2006. Isolation of salt-sensitive mutants of Sinorhizobium meliloti strain Rm1021. Microbiology 152:2049-2059.

Miyamoto, E., Watanabe, F., Charles, T. C., Yamaji, R., Inui, H., and Nakano, Y. 2003. Purification and characterization of homodimeric methylmalonyl-CoA mutase from Sinorhizobium meliloti. Arch. Microbiol. 180:151-154.

Oresnik, I. J., Liu, S. L., Yost, C. K., and Hynes, M. F. 2000. Megaplasmid pRme2011a of Sinorhizobium meliloti is not required for viability. J. Bacteriol. 182:3582-3586.

Parke, D., and Ornston, L. N. 1984. Nutritional diversity of Rhizobiaceae revealed by auxanography. J. Gen. Microbiol. 130:1743-1750. 
Parker, C. A., and Graham, P. H. 1964. Diagnostic feature in the characterization of the root-nodule bacteria of legumes. Plant Soil 3:383-395.

Persson, B., Kallberg, Y., Oppermann, U., and Jörnvall, H. 2003. Coenzyme-based functional assignments of short-chain dehydrogenases/ reductases (SDRs). Chem. Biol. Interact. 143-144:271-278.

Pobigaylo, N., Wetter, D., Szymczak, S., Schiller, U., Kurtz, S., Meyer, F., Nattkemper, T. W., and Becker, A. 2006. Construction of a large signature-tagged mini-Tn5 transposon library and its application to mutagenesis of Sinorhizobium meliloti. Appl. Environ. Microbiol. 72:43294337.

Ramu, C., Sugawara, H., Koike, T., Lopez, R., Gibson, T. J., Higgins, D. G., and Thompson, J. D. 2003. Multiple sequence alignment with the Clustal series of programs. Nucleic Acids Res. 31:3497-3500.

Richardson, J. S., Hynes, M. F., and Oresnik, I. J. 2004. A genetic locus necessary for rhamnose uptake and catabolism in Rhizobium leguminosarum bv. trifolii. J. Bacteriol. 186:8433-8442.

Rüberg, S., Tian, Z. X., Krol, E., Linke, B., Meyer, F., Wang, Y., Pühler, A., Weidner, S., and Becker, A. 2003. Construction and validation of a Sinorhizobium meliloti whole genome DNA microarray: Genome-wide profiling of osmoadaptive gene expression. J. Biotechnol. 106:255-268.

Schroeder, B. K., House, B. L., Mortimer, M. W., Yurgel, S. N., Maloney, S. C., Ward, K. L., and Kahn, M. L. 2005. Development of a functional genomics platform for Sinorhizobium meliloti: Construction of an ORFeome. Appl. Environ. Microbiol. 71:5858-5864.

Sivaraman, S., Sullivan, T. J., Johnson, F., Novichenok, P., Cui, G. Simmerling, C., and Tonge, P. J. 2004. Inhibition of the bacterial enoyl reductase FabI by triclosan: A structure-reactivity analysis of FabI inhibition by triclosan analogues. J. Med. Chem. 47:509-518.

Tombolini, R., Povolo, S., Buson, A., Squartini, A., and Nuti, M. P. 1995. Poly-beta-hydroxybutyrate (PHB) biosynthetic genes in Rhizobium meliloti 41. Microbiology 141:2553-2559.
Wang, C., Meek, D. J., Panchal, P., Boruvka, N., Archibald, F. S., Driscoll, B. T., and Charles, T. C. 2006. Isolation of poly-3-hydroxybutyrate metabolism genes from complex microbial communities by phenotypic complementation of bacterial mutants. Appl. Environ. Microbiol. 72:384-391.

Williams, K. P., Sobral, B. W., and Dickerman, A. W. 2007. A robust species tree for the alphaproteobacteria. J. Bacteriol. 189:4578-4586.

Wood, D. W., Setubal, J. C., Kaul, R., Monks, D. E., Kitajima, J. P. Okura, V. K., Zhou, Y., Chen, L., Wood, G. E., Almeida, N. F., Jr., Woo, L., Chen, Y., Paulsen, I. T., Eisen, J. A., Karp, P. D., Bovee, D., Sr., Chapman, P., Clendenning, J., Deatherage, G., Gillet, W., Grant, C., Kutyavin, T., Levy, R., Li, M. J., McClelland, E., Palmieri, A., Raymond, C., Rouse, G., Saenphimmachak, C., Wu, Z., Romero, P. Gordon, D., Zhang, S., Yoo, H., Tao, Y., Biddle, P., Jung, M., Krespan, W., Perry, M., Gordon-Kamm, B., Liao, L., Kim, S., Hendrick, C., Zhao, Z. Y., Dolan, M., Chumley, F., Tingey, S. V., Tomb, J. F., Gordon, M. P., Olson, M. V., and Nester, E. W. 2001. The genome of the natural genetic engineer Agrobacterium tumefaciens C58. Science 294:23172323

Young, J. P., Crossman, L. C., Johnston, A. W., Thomson, N. R., Ghazoui, Z. F., Hull, K. H., Wexler, M., Curson, A. R., Todd, J. D., Poole, P. S., Mauchline, T. H., East, A. K., Quail, M. A., Churcher, C., Arrowsmith, C., Cherevach, I., Chillingworth, T., Clarke, K., Cronin, A., Davis, P., Fraser, A., Hance, Z., Hauser, H., Jagels, K., Moule, S., Mungall, K., Norbertczak, H., Rabbinowitsch, E., Sanders, M., Simmonds, M., Whitehead, S., and Parkhill, J. 2006. The genome of Rhizobium leguminosarum has recognizable core and accessory components. Genome Biol. 7:R34.

Yuan, Z. C., Zaheer, R., and Finan, T. M. 2006. Regulation and properties of PstSCAB, a high-affinity, high-velocity phosphate transport system of Sinorhizobium meliloti. J. Bacteriol. 188:1089-1102. 